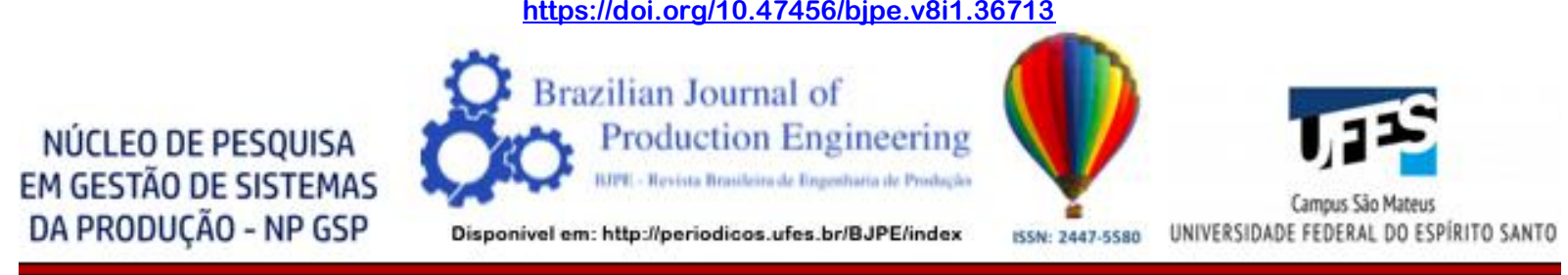

ARTIGO ORIGINAL

OPEN ACCESS

\title{
ANÁLISE DO PROCESSO DE ENVASE DE GLP: FOCO NA MELHORIA CONTÍNUA
}

\section{ANALYSIS OF THE LPG BOTTLING PROCESS: FOCUS ON CONTINUOUS IMPROVEMENT}

\author{
Jorge Luiz Rosa ${ }^{1 *}$, Marco Aurélio Feriotti ${ }^{2}$, Alexandre Formigoni ${ }^{3}$, \\ Mayara Neves Pohlmann ${ }^{4}$, \& Rosinei Batista Ribeiro ${ }^{5}$ \\ 12345 Centro Estadual de Educação Tecnológica Paula Souza - CEEPTS. \\ 1 jorge.rosa2@fatec.sp.gov.br ${ }^{2}$ marco.a.feriotti@gmail.com ${ }^{3}$ alexandre.formigoni@ fatec.sp.gov.br \\ ${ }^{4}$ mayara.pohlmann@gmail.com ${ }^{5}$ rosinei1971@gmail.com
}

\section{ARTIGO INFO.}

\section{Recebido em: 22.09.2021}

Aprovado em: 26.10.2021

Disponibilizado em: 31.01.2022

\section{Palavras-chave:}

Produção Enxuta; Mapeamento de Processos;

Melhoria Contínua; SIPOC.

\section{KEYWORDS:}

Lean Manufacturing; Process Mapping; Continuous Improvement; SIPOC.

*Autor Correspondente: Rosa, J. L.

\section{RESUMO}

Atualmente a indústria tem uma constante necessidade de utilizar de forma eficiente os recursos que possui. Desta forma nenhuma proposta de melhoria deveria ser ignorada e, sim estudada, a fim de se extrair o máximo de aproveitamento, desde o ganho em eficiência propriamente dito quanto ao conhecimento para futuros desenvolvimentos. Buscando melhorar os processos existentes na planta da empresa Ultragaz, em São José dos Campos-SP, desenvolveu-se um estudo objetivando a melhoria dos processos operados na mesma planta. A partir do mapeamento dos processos, identificar os pontos que são passíveis de melhorias e a partir daí elaborar, implementar e acompanhar as alterações propostas, identificando assim as perdas ou desperdícios serem minimizadas. Foram identificados ao longo do ano de 2017 dois processos a serem melhorados: o Tratamento de Efluentes e o Deslocamento e Transporte de Vasilhames pertencentes a outras marcas. Nos dois casos foram identificadas ineficiências e oportunidade de melhorias.

\begin{abstract}
Currently, the industry has a constant need to efficiently use the resources it has. In this way, no proposal for improvement should be ignored, but rather studied, in order to the extract the maximum benefit, from the gain in efficiency itself regarding knowledge for future developments. Seeking to improve the existing processes at the Ultragaz company's plant, in São José dos Campos-SP, a study was developed with the aim of optimizing the processes developed at the same plant. From the mapping of processes, identify the processes that can be improved and from there, prepare, implement and monitor the proposed changes, thus identifying inefficiencies to be minimized. During 2017, two processes were identified to be improved: The Treatment of Effluents and the Displacement and Transport of Containers belonging to other brands. In both cases, inefficiencies and opportunities for improvement were identified.
\end{abstract}




\section{INTRODUÇÃO}

De acordo com sua lei de fundação, a Empresa de Pesquisa Energética tem a função de elaborar e publicar o Balanço Energético Nacional (BEN) todos os anos para manter a prática iniciada pelo Ministério de Minas e Energia O objetivo do BEN é apresentar a oferta e o consumo de energia do Brasil, abrangendo a extração de recursos energéticos primários, sua conversão em energia secundária, importação e exportação, distribuição e uso final de energia. O Relatório Abrangente do BEN de 2020 - o ano-base de 2019, fornece informações abrangentes sobre o uso de energia, incluindo o gás liquefeito de petróleo (GLP) no Brasil e os padrões de uso em 2019.

O GLP é um dos produtos mais utilizados no país. Tem como principais finalidades a cocção de alimentos, a geração de calor e energia (combustível). Na sua forma a granel, é muito utilizado por hospitais, condomínios residenciais e indústrias. Considerado uma das fontes de energia mais econômica, prática e limpa, o GLP é combustível seguro que pode ser facilmente transportado para longas distâncias e lugares menos acessíveis. Atualmente, a distribuição do GLP é um dos serviços mais abrangentes no país.

Em relação as suas propriedades físicas é importante ressaltar que o GLP, como outros gases comercializados na forma granel, é armazenado sobre pressão e parte dele se mantém na forma líquida. Ao ser consumido, troca de estado físico: de líquido para vapor. Em outras palavras, isto ocorre na abertura da válvula de escape, onde a pressão é liberada e a parte líquida vaporiza expulsando o gás para fora do vasilhame ou tanque. As temperaturas internas e externas dos recipientes, juntamente com a densidade do produto, fazem variar a sua pressão. Este fato obriga que os tanques de GLP, por segurança, não sejam abastecidos ao seu máximo. Normalmente, se perde algo em torno de $15 \%$ da capacidade de armazenagem do recipiente. Em condições normais, sem vaporizadores, o gás precisa estar acima deste percentual para ter pressão e poder ser consumido. O lastro operacional varia de acordo com o tipo de produto, recipiente de armazenagem, densidade e temperatura. No caso do GLP, normalmente, gira em torno de $30 \%$ da capacidade dos tanques utilizados para armazenagem.

A comercialização do GLP pode ser realizada em diferentes tipos vasilhames, com capacidades que variam entre 2 a $90 \mathrm{~kg}$. A forma mais comum é o P-13 (botijão de $13 \mathrm{Kg}$ ), utilizado em residências para cocção de alimentos. Sua utilização cor responde a mais de $90 \%$ do consumo brasileiro, sendo que o setor residencial sozinho responde por aproximadamente 80\% do consumo total de GLP do país (Fernandes et al., 2020).

O aumento de preços do botijão de gás continua a representar uma parcela considerável nos orçamentos familiares dos consumidores de baixa renda. Todavia, este tem sido um tema extremamente sensível a todos os governos brasileiros, sem distinção de linha política, desde 1970, quando começou a difusão do consumo de GLP no país (Araújo, 2018).

Nos últimos anos, têm sido recorrentes as teses de que o enchimento fracionado de recipientes transportáveis e a comercialização de GLP em recipientes de outras marcas iriam reduzir os custos de distribuição e revenda, promovendo a queda de preços (Araújo, 2018).

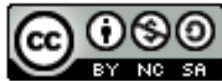


Para lidar com essa problemática, surge a pergunta de como a melhoria dos processos operados na mesma planta podem aumentar a eficiência e reduzir os custos operacionais?

Nesse sentido, esse artigo tem como objetivo analisar o processo de envasamento do GLP na planta da empresa Ultragaz, em São José dos Campos-SP, mapear os processos, identificar os pontos que são passíveis de melhorias e a partir daí elaborar, implementar e acompanhar as alterações propostas.

Este artigo possui natureza aplicada com objetivos exploratórios e uma abordagem qualiquantitativa. Os procedimentos técnicos adotados foram um estudo de caso acompanhado por uma revisão bibliográfica de maneira que ambos deram o embasamento necessário para a avaliação dos resultados da aplicação da melhoria contínua.

\section{FUNDAMENTAÇÃO TEÓRICA}

\section{Mapeamento do processo}

Todo e qualquer produto ou serviço entregue a um cliente necessita de um processo para sua realização, sendo o processo qualquer atividade ou conjunto de atividades que a partir de um input, adiciona valor a ele e fornece um output a um cliente específico (Gonçalves, 2000).

Trata-se de uma ferramenta gerencial analítica e de comunicação e é essencial aos líderes das organizações que possuem o objetivo de promover melhorias ou implantar uma estrutura voltada para novos processos (Villela et al., 2000).

Permite a detecção de falhas e oportunidades de melhoria, facilitando a identificação de tarefas críticas e eliminando tarefas que não agregam valores ou que gerem gargalos (Mello, 2005).

Segundo Hunt (1996), esta análise estruturada de processos permite ainda reduzir custos no desenvolvimento de produtos e serviços, falhas de integração entre sistemas e promover melhoria de desempenho organizacional, somando a isso o melhor entendimento dos processos atuais.

De acordo com Mello e Salgado (2005), para gerenciar um processo é necessário primeiramente, visualizá-lo. O mapeamento é realizado para representar as diversas tarefas necessárias e a sequência como elas ocorrem.

Basicamente consiste na obtenção de um modelo que represente de forma satisfatória a realidade, ou seja, que obtenha um funcionamento sistêmico dos processos da empresa de forma analisá-los por módulos. Para isso, utilizam-se ferramentas de representação diagramada, como: Fluxogramas, Integrated Definition Language (IDEF), Supplier, Input, Process, Outputs and Customer (SIPOC) entre outros.

\section{Fluxograma}

Para Pyzdek e Keller (2011) o fluxograma é uma ferramenta gráfica que tem como objetivo descrever o fluxo do processo, em que cada tarefa é representada por símbolos, que seguem um padrão ANSI (American National Standards Institute), para se adequar a cada ação desenvolvida no processo. 
O fluxograma é a representação gráfica que apresenta a sequência de um trabalho de forma analítica, caracterizando as operações, os responsáveis e ou unidades organizacionais envolvidas nos processos. Também pode-se definir o fluxograma como um diagrama que mostra uma sequência analítica de um determinado processo. $O$ fluxograma possibilita também uma preparação para o aperfeiçoamento de processos empresariais (Oliveira, 2006).

\section{SIPOC - Suppliers Inputs Process Outputs Customers}

Na melhoria de processos, um SIPOC é uma ferramenta que resume as entradas e saídas de um ou mais processos em forma de tabela. A sigla SIPOC significa suppliers (fornecedores), inputs (entradas), process (processo), outputs (saídas) e customers (clientes), que formam as colunas da tabela (Simon, 2018).

Um diagrama SIPOC é uma ferramenta usada por uma equipe para identificar todos os elementos relevantes de um projeto de melhoria de processo antes do trabalho começar. Ajuda a definir um projeto complexo que pode não ter um escopo bem definido e é normalmente empregado na fase de Medição da metodologia Six Sigma DMAIC (Definir, Medir, Analisar, Melhorar, Controlar). É semelhante e relacionado ao mapeamento de processos e ferramentas 'dentro / fora do escopo ', mas fornece detalhes adicionais (Simon, 2018).

De acordo com Andrade (2012), com uma visão mais clara do fluxo dos processos, é possível realizar melhorias destes de modo que por futuras ações seja obtido um nível de qualidade ainda maior de acordo com as informações obtidas, tais como:

- Fronteira do projeto, onde inicia e onde termina o campo de atuação;

- Lista de entradas e saídas do processo e seus respectivos fornecedores e cliente. Esta informação é fundamental na definição da equipe de trabalho;

- Especificações atuais para as entradas e saídas do processo. Neste ponto normalmente são detectadas falhas ou falta de especificações.

\section{Just in Time}

O sistema Just in Time (no tempo justo) surgiu no Japão na década de 60, criado pela Toyota Motor Company com o intuito de possuir um sistema de gestão que pudesse controlar a produção, sendo assim, conhecido como Sistema Toyota de Produção.

De acordo com Correa e Gianesi (1993), o principal objetivo do sistema JIT é a melhoria contínua. Os estoques têm sido usados para evitar descontinuidades no processo produtivo, as quais são causadas por três tipos de problema: de qualidade, de quebra de máquina e de preparação de máquina. A redução dos estoques contribui para que exista maior visibilidade dos problemas. Sendo assim, pode-se afirmar que o JIT contribui para a identificação dos problemas, tornando mais fácil eliminá-los.

\section{História do Gás Liquefeito de Petróleo (GLP) no Brasil}

A história do gás liquefeito de petróleo (GLP) no Brasil iniciou literalmente de forma trágica e acidental, tendo como estopim uma trágica explosão do dirigível alemão Hindenburg, ocorrido nos Estados Unidos da América (USA) em maio de 1937. Na época, o Brasil tinha uma base de dirigíveis na cidade do Rio de Janeiro com um grande estoque de propano, 
combustível utilizado em seus motores. Porém, com a grande repercussão negativa do acidente, esse estoque ficou parado, pois a população não confiava mais no meio de transporte. Com isso, cerca de 6 mil cilindros estocados no Brasil foram colocados à venda pela Companhia Aérea Graf Zepellin e foi comprado pelo imigrante austríaco radicado no Brasil, Ernesto Igel, que teve a ideia de utilizar os botijões de gás como combustível para fogões domésticos, em alternativa ao carvão vegetal e ao querosene utilizados tradicionalmente, iniciando assim o ciclo de GLP no Brasil.

Em 1954 o governo brasileiro iniciou a produção do combustível em solo nacional com a criação da primeira refinaria brasileira na cidade de Mataripe (BA), pois até então, o GLP era importado dos Estados Unidos. No ano seguinte, em 1955, a produção nacional se intensifica com a construção das refinarias da Petrobrás (Sindigás).

\section{Mercado Brasileiro de GLP}

O BEN se mostra como uma importante ferramenta de pesquisas relacionadas ao planejamento nacional de energia, pois fornece estatísticas confiáveis e frequentemente revela tendências no fornecimento e consumo de energia servindo como referência para os dados nacionais de energia. No Brasil, a demanda de GLP representa cerca de 5,4\% da matriz energética (Figura 1), sendo que oitenta por cento deste volume é consumido por residências, que em sua grande maioria utilizam essa fonte energética para cocção de alimentos. O GLP é a fonte de energia com maior penetração nacional, atingindo 95\% do território nacional (BEN, 2020).

Figura 1. Gráfico da Matriz Energética Brasileira (2020).

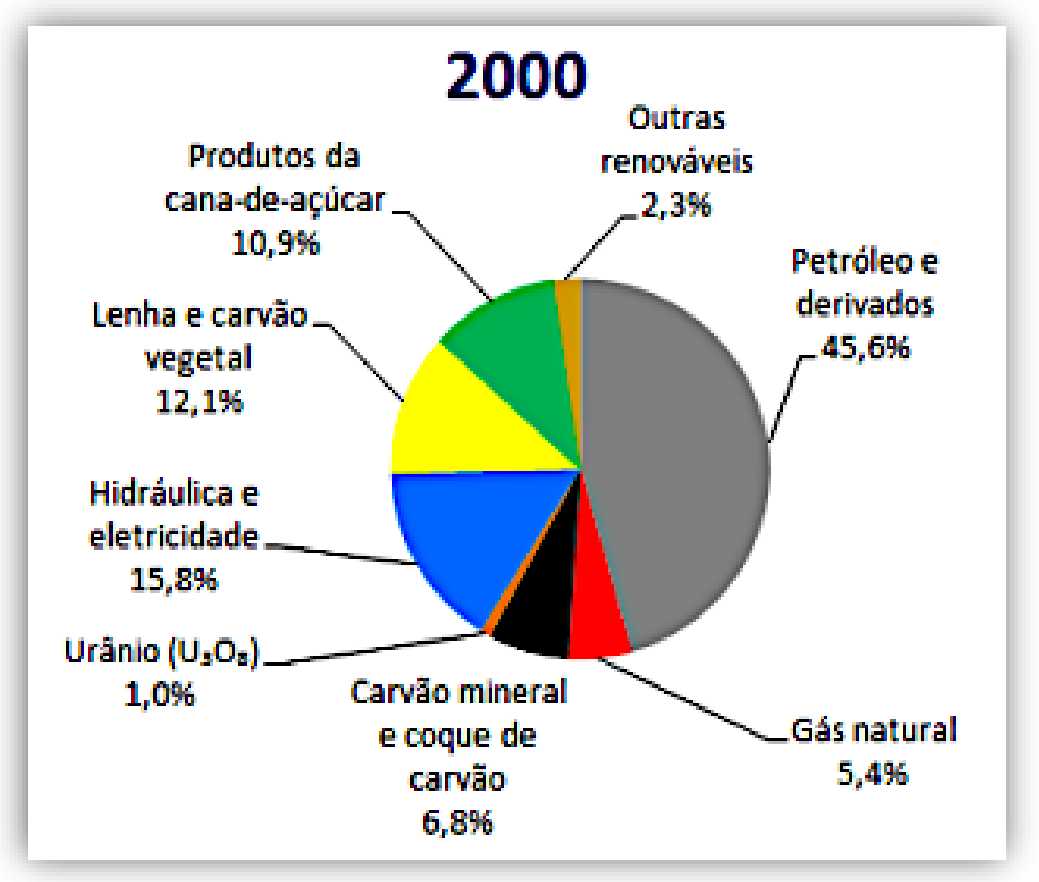

Fonte: BEN 2020

Analisando melhor o consumo de GLP no Brasil (Figura 2), constata-se que $80 \%$ do volume é destinado a residências e os outros $20 \%$ é utilizado por outros setores como: indústria, comércio, setores públicos e agropecuária.

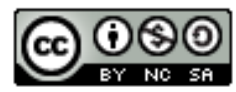


Figura 2. Gráfico do Perfil de Consumo de GLP no Brasil (2019).

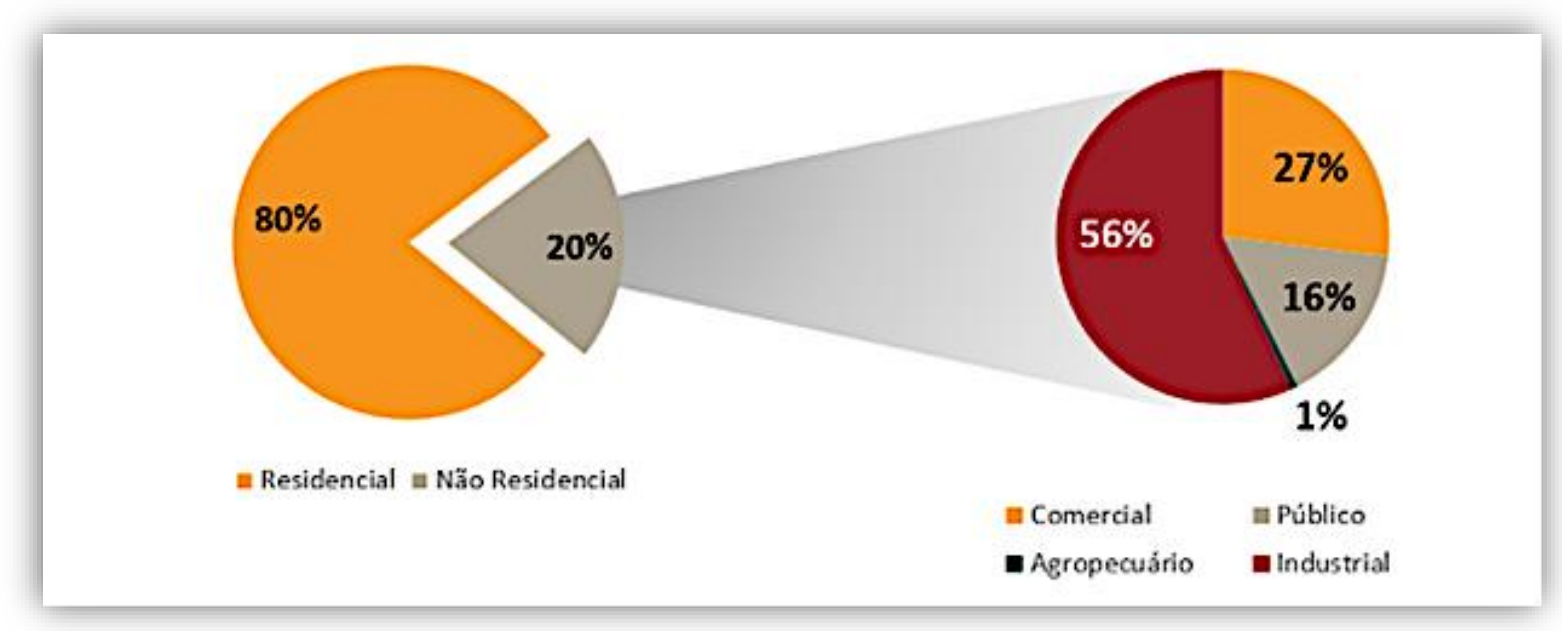

Fonte: Plano Decenal de Expansão de Energia 2022, BEN 2020

Quando se aborda a concentração do consumo de GLP no Brasil, conforme demonstrado na Figura 3, pode-se afirmar que ele apresenta grande concentração nas regiões Sudeste e Nordeste, representando aproximadamente $68 \%$ do consumo total do país. Sendo que somente o estado de São Paulo responde por $24,7 \%$ da demanda, quase o equivalente ao total da região Nordeste (Filgueiras et al., 2015).

Figura 3. Demanda de GLP pôr região no Brasil (2020).

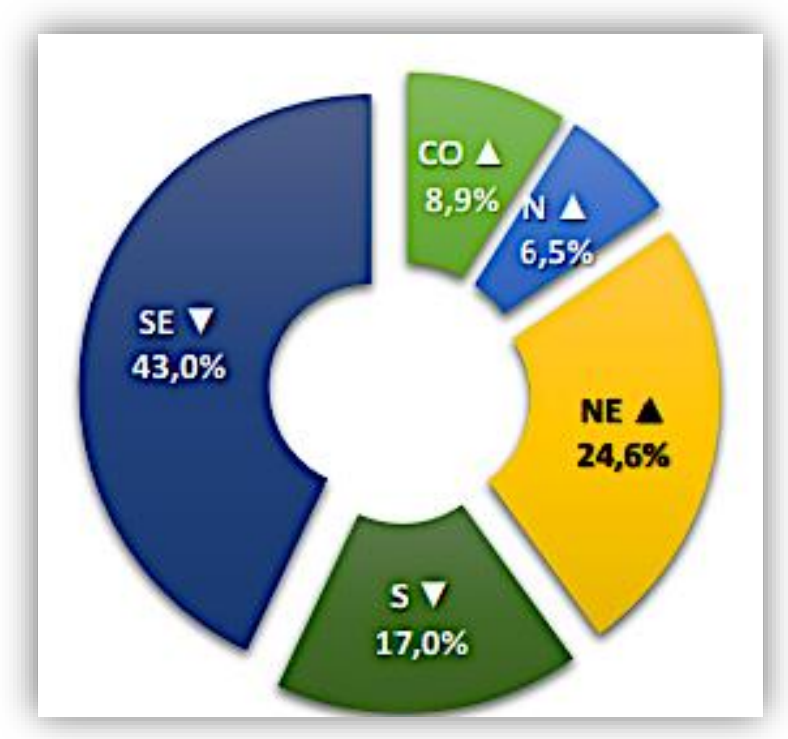

Fonte: ANP 2020

\section{Oferta de GLP no Brasil}

O GLP consumido no país tem como principais polos produtores as refinarias e as unidades de processamento de gás natural (UPGNs). Além desses locais, existe uma pequena produção que é oferecida pela SIX (Unidade de Industrialização de Xisto), localizada no Paraná (Figura 4).

\section{$@ \odot \Theta \odot$}


Figura 4. Localização e Produção de GLP no Brasil (2020)

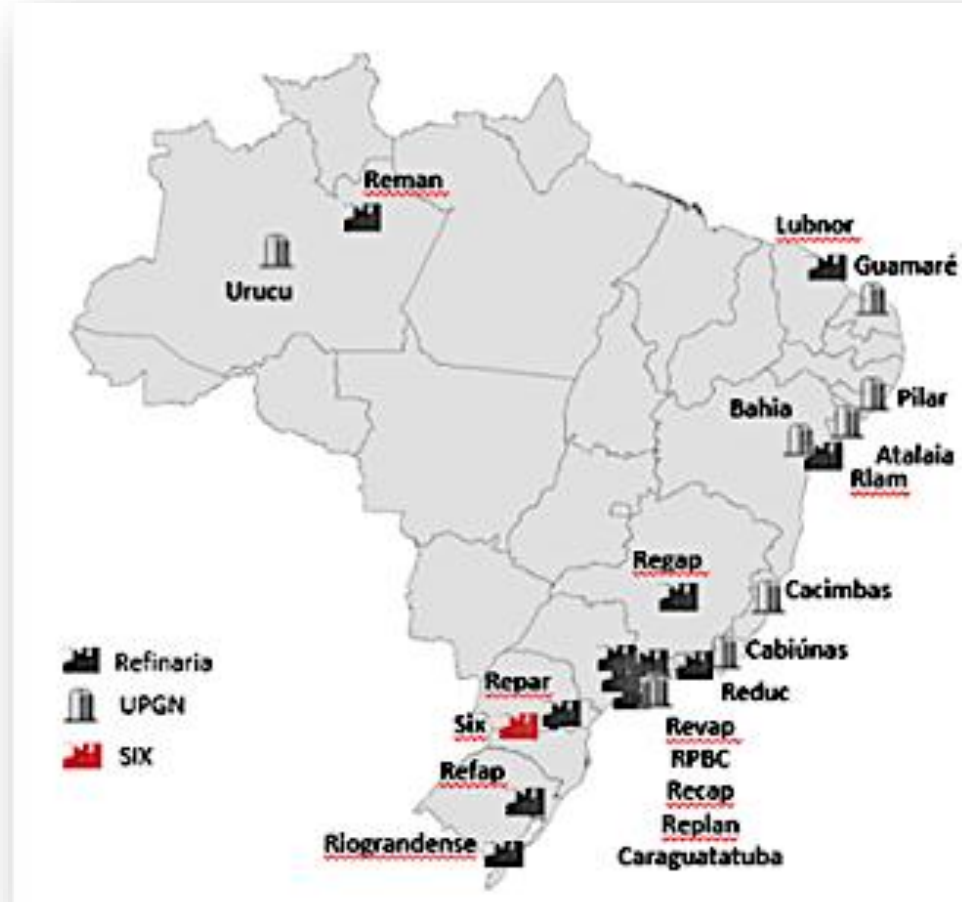

\begin{tabular}{|c|c|}
\hline Polo & $\begin{array}{c}\text { Produção 2013 } \\
\text { (tons/dia) }\end{array}$ \\
\hline Replan (SP) & 2.436 \\
\hline Rlam (BA) & 1.663 \\
\hline Reduc (RJ) & 1.479 \\
\hline Revap (SP) & 1.455 \\
\hline Refap (RS) & 1.359 \\
\hline Reoar (PR) & 1.326 \\
\hline Urucu (AM) & 1.216 \\
\hline Regap (MG) & 1.088 \\
\hline Cacimbas (ES) & 836 \\
\hline Cabiùnas (RJ) & 784 \\
\hline RPBC (SP) & 529 \\
\hline Recap (SP) & 507 \\
\hline Bahia (BA) & 285 \\
\hline Guamaré (RN) & 282 \\
\hline Atalaia (SE) & 208 \\
\hline Reman (AM) & 118 \\
\hline Caraguatatuba (SP) & 118 \\
\hline Pilar (AL) & 90 \\
\hline Riograndense (RS) & 41 \\
\hline SIX (PR) & 33 \\
\hline Lubnor (CE) & 14 \\
\hline
\end{tabular}

Fonte: ANP (2020).

Segundo o IBP - 2015 (Instituto Brasileiro de Petróleo, Gás e Biocombustíveis), apesar do aumento de demanda de 18\% nos últimos 11 anos (2003 até 2013), a produção nacional passou de 5,2 milhões de toneladas em 2003 para 5,5 milhões de toneladas um aumento de $6 \%$ em 2013. Dessa forma, para suprir esta demanda foi necessário aumentar a importação em 63\% de 2003 à 2013 (Figura 5), passando de 1,1 para 1,84 milhões de toneladas, aumentando assim a dependência externa de $18 \%$ para $25 \%$ do consumo nacional.

Figura 4. Aumento da importação do GLP no Brasil 2003 à 2013

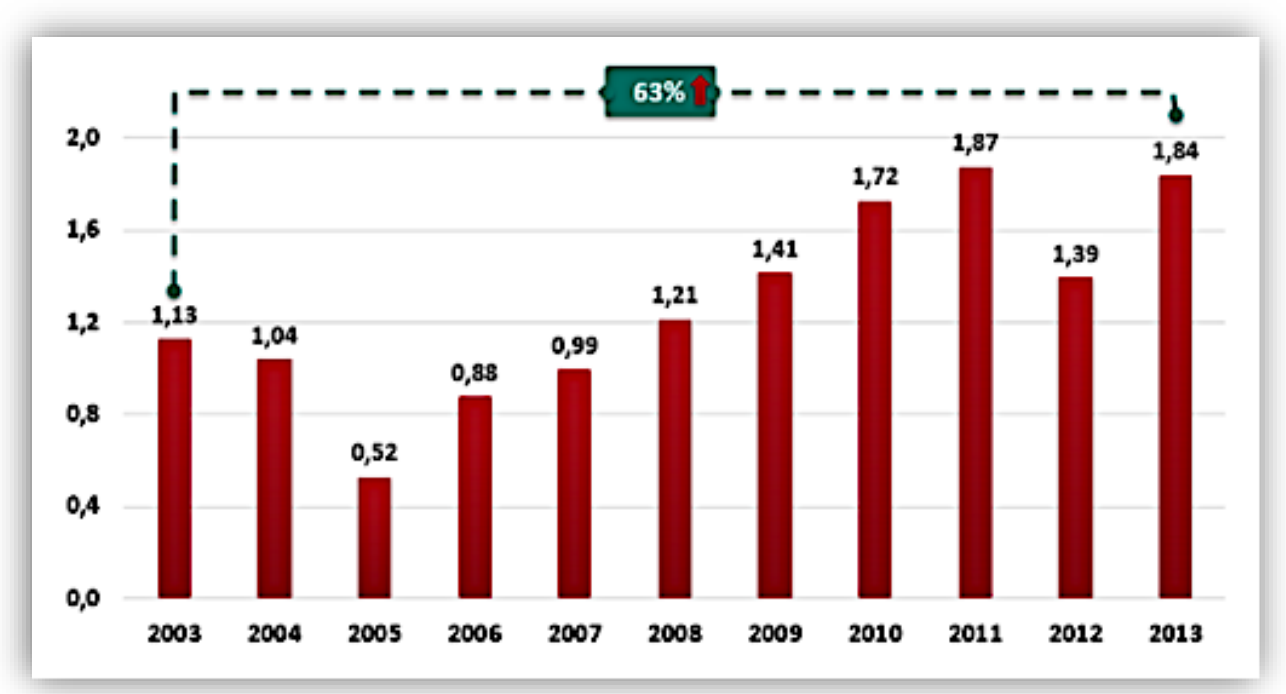

Fonte: ANP (2015)

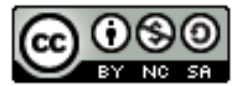




\section{MÉTODO}

\section{Estudo de Caso}

O presente estudo foi realizado com base em informações da Companhia Ultragaz S/A, mais precisamente na sua filial da cidade de São José dos Campos, uma das principais distribuidoras de GLP do interior do estado de São Paulo. As situações e problemas apresentados são comuns a várias outras filiais que também realizam o engarrafamento de granéis líquidos, gases, água, etc. No segmento empresarial, o projeto Ultraflex busca a prospecção e retenção de novos clientes, além do acerto nas decisões de investimento e eficiência na distribuição do GLP.

\section{Produto do segmento domiciliar e comercial}

No segmento domiciliar, o GLP pode vir acondicionado em diferentes tipos de recipientes. Eles são padronizados e variam de acordo com a utilização e as necessidades dos consumidores:

a) P2: O botijão portátil de $2 \mathrm{~kg}$ (Figura 5) é indicado para fogareiros de acampamento e lampiões. Esse produto não é adaptável aos reguladores de pressão e não deve ser usado em fogões comuns.

Figura 5. Botijão de $2 \mathrm{Kg}$.

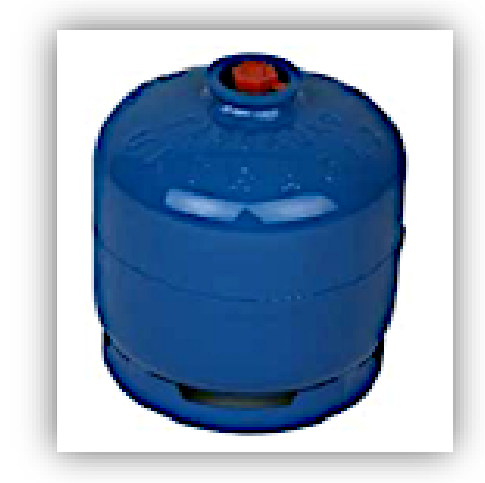

Fonte: Autores (2021).

b) P5: O botijão de $5 \mathrm{~kg}$, (Figura 6) é utilizado em fogões residenciais. Instalação e manuseio são semelhantes aos do botijão de $13 \mathrm{~kg}$. Dimensões: 272,5 mm (diâmetro) x $333 \mathrm{~mm}$ (altura).

Figura 6. Botijão de $5 \mathrm{Kg}$

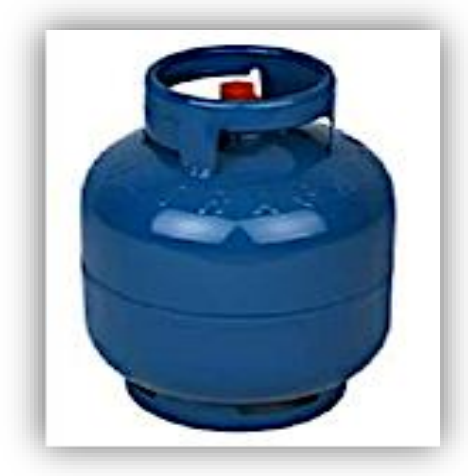

Fonte: Autores (2021).

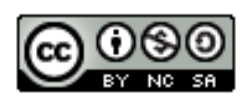


c) P13: O vasilhame de $13 \mathrm{~kg}$ (Figura 7) é o mais utilizado para cozinhar alimentos em fogões residenciais. Dimensões: 360 mm (diâmetro) x $460 \mathrm{~mm}$ (altura).

Figura 7. Botijão de $13 \mathrm{Kg}$

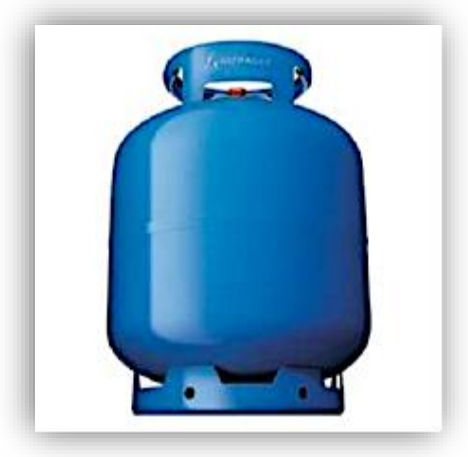

Fonte: Autores (2021).

d) P20: O GLP também pode ser utilizado como combustível para motores de veículos. No Brasil, esse uso é liberado apenas para empilhadeiras. Existe um cilindro de $20 \mathrm{~kg}$ específico para essa finalidade (Figura 8). É o único recipiente de GLP que deve ser usado na horizontal, pois todo o seu sistema é projetado para o funcionamento nessa posição, na dimensão $309 \mathrm{~mm}$ x $885 \mathrm{~mm}$.

Figura 8. Botijão de $20 \mathrm{Kg}$

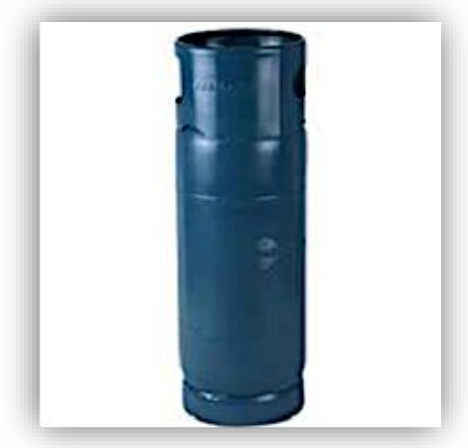

Fonte: Autores (2021).

e) P45: Esse produto é utilizado em larga escala e em diferentes situações e locais, tais como residências, comércio, bares, restaurantes, lavanderias, indústrias, hospitais e escolas. São instalados em centrais de abastecimento, em locais predeterminados pelos clientes (Figura 9). Dimensões: 380 mm (diâmetro) x 1280 mm (altura).

Figura 9. Botijão de $45 \mathrm{Kg}$

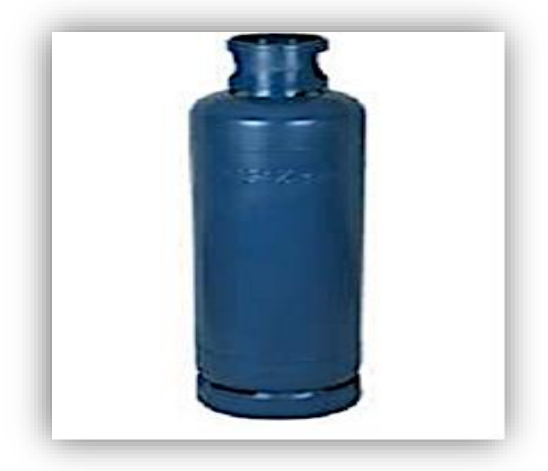

Fonte: Autores (2021).

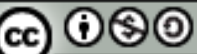




\section{Linha de Produção}

Assim que os botijões chegam à base de produção, a equipe de descarga realiza a seleção visual (inspeção) de $100 \%$ dos botijões. Os botijões em bom estado são enviados para o envase. Já aqueles que estão sem condições de uso são enviados para a requalificação, manutenção ou sucateamento. Em seguida, a tara (peso dos botijões vazios) é registrada no próprio botijão.

Os botijões são encaminhados ao carrossel eletrônico, onde o enchimento do GLP líquido é feito com toda a precisão. Após passar pelo processo de enchimento, todos os botijões são repesados, para garantir que o consumidor receba o produto com o peso certo.

A segurança é um fator muito importante para este tipo de produto. Por isso todos os botijões passam por uma verificação automática de vazamentos. O botijão também passa por um equipamento que faz o teste do anel o'ring de vedação da válvula, assim como em outros itens importantes e que garantem a segurança do botijão.

Finalmente, os botijões são colocados em caminhões e saem da base de produção, prontos para chegar à casa do consumidor.

Figura 10. Etapas do processo de produção

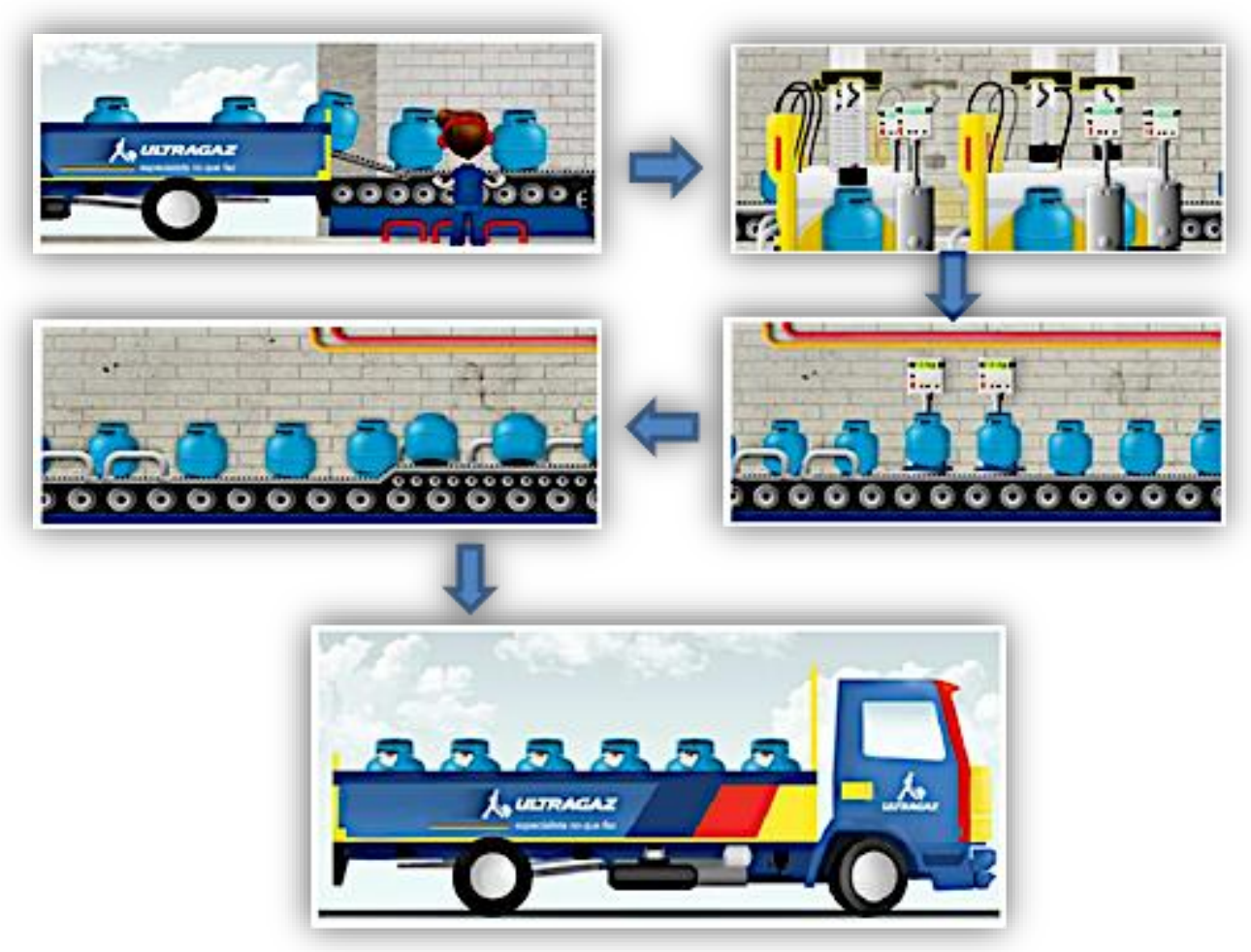

Fonte: Adaptado de https://www.ultragaz.com.br/residencial/linha-de-producao

\section{ANÁLISE DOS PROCESSOS}

Analisando os subprocessos do envase de GLP e envolvendo áreas como gestão da produção, manutenção, suprimentos e comercial; foi possível identificar quais deles possuíam potencial de melhoria e otimização. Esta verificação levou em consideração: potencial de melhoria do

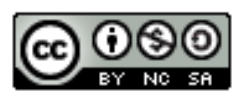



GLP: foco na melhoria contínua. Brazilian Journal of Production Engineering, 8(1), 01-17.

produto, redução de custo, aspectos ambientais, agilidade e confiabilidade no suprimento e melhoria das condições de serviço.

Para a verificação foram mapeados os principais processos através de fluxogramas, SIPOC e análise e projeção de resultados dentro da cadeia produtiva.

Por meio da análise e sinergia entre as áreas durante o ano, chegou-se à conclusão de que os principais projetos de melhoria na planta da Ultragaz no ano de 2017 seriam:

-Implantação de uma ETAR - Estação de tratamento Águas Residuais.

•Projeto e análise de viabilidade de Transportador Móvel para Botijões P13.

\section{Estação de Tratamento de Água Residuais - ETAR}

Toda água utilizada nos processos produtivos era separada e armazenada para ser encaminhada a uma empresa prestadora de serviços de tratamento de efluentes. Esta operação tinha um custo mensal de $\mathrm{R} \$ 8.000,00$, eram tratados $1.200 \mathrm{~m}^{3}$ de água utilizada no processo produtivo.

Este processo acabava gerando demandas de movimentações de galões e ocupando espaço físico de armazenamento que poderia ser utilizado em outros processos.

Com o objetivo de otimizar este processo e reduzir custos operacionais, foram realizados diversos estudos para a implantação de uma planta de tratamento de efluentes na unidade de produção da Ultragaz em São José dos Campos, assim como verificada a viabilidade da instalação e os impactos de sua implantação.

Após estudos e análises, indicou-se a aquisição de uma estação de tratamento compacta, a ETAR-2000 Evolution (Figura 11) para o tratamento dos efluentes. Essa estação de tratamento compacta possui como principais especificações o tratamento e reuso de água de lavagem de veículos contaminada com material em suspensão (argilas, óleos, graxas e sabões).

Este sistema possui capacidade de tratamento de $2,0 \mathrm{~m}^{3} / \mathrm{h}$ e é constituída basicamente por seis (6) operações unitárias: ajuste de pH, coagulação, floculação, separação por flotação, geração de microbolhas e filtração por areia; seu peso é de $200 \mathrm{~kg}$ e a potência instalada de $4 \mathrm{cv}$.

Figura 11. ETAR Evolution 2000.

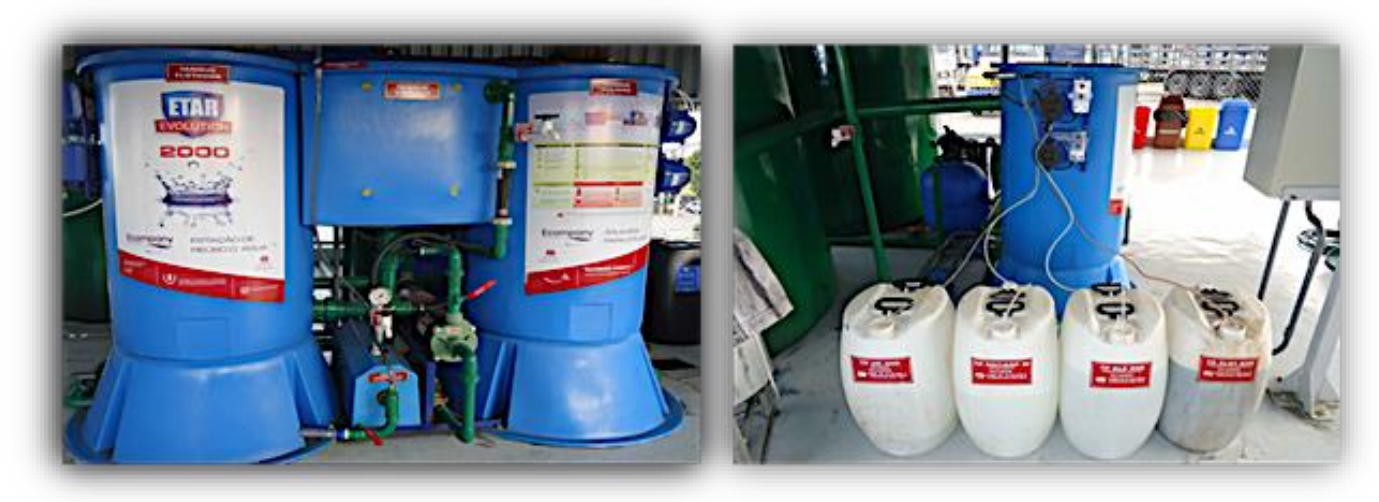

Fonte: Autores (Ultragaz- unidade São José dos Campos, 2017)

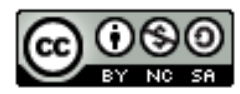



GLP: foco na melhoria contínua. Brazilian Journal of Production Engineering, 8(1), 01-17.

Após a instalação e efetuadas as devidas medições e coletas de resultados, foi verificado que o processo passou a trabalhar mais alinhada e integrada a demanda do setor de produção e manutenção. Pois o processo de tratamento passou a funcionar de forma simultânea ao processo de lavagem e envase dos vasilhames.

Após a implantação da ETAR o volume de água utilizado reduziu para $300 \mathrm{~m}^{3}$ a cada 2 meses, pois a água tratada passou a ser reutilizada no processo; tendo assim um ganho tangível com a redução do custo com a prestação de serviços, do volume de água gasto e otimização do processo; assim como intangível que é a adequação ambiental da empresa um dos pilares propostos pela companhia.

Ainda após o cálculo de viabilidade estima-se que o retorno do investimento se dará em 24 meses.

\section{Transporte, Carregamento e Descarregamento de BotiJões P-13}

Atualmente estima-se que de 4 a 10\% do Produto Interno Bruto (PIB) dos países sejam perdidos por doenças e agravos ocupacionais (International Labour Organization, 2003). Por isso, é cada vez maior a preocupação das empresas com o bem-estar e a integridade física dos trabalhadores, pois impacta diretamente na gestão e sucesso de um negócio (Diniz, 2005).

Este projeto teve início após a análise do processo de carregamento e descarregamento de botijões do tipo P-13 (vasilhames de 13kg) no setor de destroca OM (Outras Marcas) na base 2 da unidade de envase (Figura 12).

Figura 12. Processo de Movimentação de Vasilhames OM.

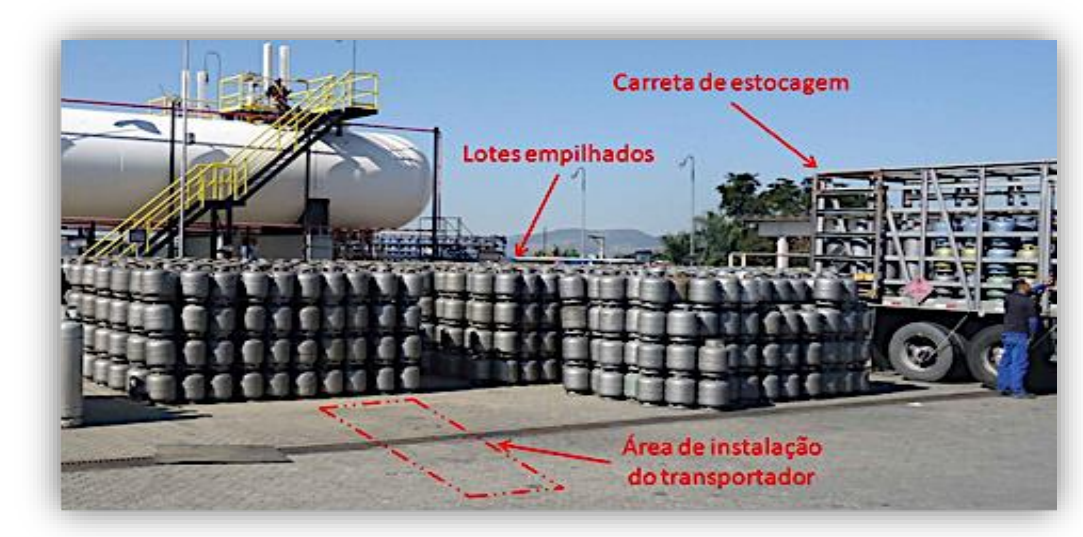

Fonte: Autores (Ultragaz- unidade São José dos Campos, 2017)

Na empresa são necessários seis funcionários posicionados em forma de linha de transporte para estocagem ou remoção dos botijões na carreta. Buscando otimizar o processo e solucionar essa deficiência, foi projetado e desenvolvido um protótipo de transportador em ângulo, melhorando assim: a segurança e qualidade de trabalho dos funcionários envolvidos e a conservação do acabamento do produto.

O carregamento e descarregamento total dos botijões na carreta leva-se em torno de 50 minutos. Pode-se observar que em todas as condições de operação existe um esforço braçal repetitivo para carregamento ou descarregamento dos botijões, a Figura 13 apresenta um dos cenários da operação de descarregamento.

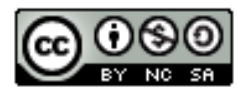



GLP: foco na melhoria contínua. Brazilian Journal of Production Engineering, 8(1), 01-17.

Figura 13. Processo de carregamento de carretas.

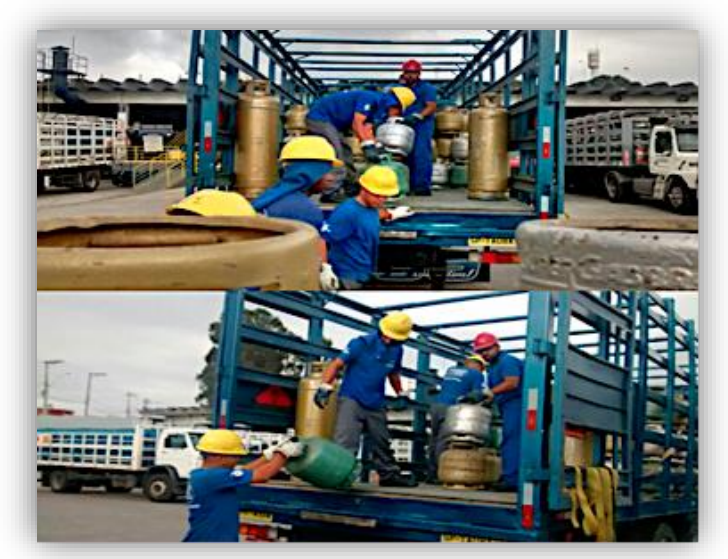

Fonte: Autores (Ultragaz- unidade São José dos Campos, 2017)

\section{Desenvolvimento do Transportador em Ângulo}

Realizadas diversas análises e estudos desse processo, envolvendo a gerência de produção e coordenação de manutenção, com o objetivo de gerar maior agilidade e eficiência, assim como beneficiar os funcionários envolvidos neste processo.

Após essa verificação chegaram ao consenso sobre o desenvolvimento de um transportador de botijões, com o objetivo de reduzir a mão de obra envolvida em pelo menos $30 \%$, de seis para quatro operadores e eliminar a utilização da carreta de estocagem.

Desenvolveu-se um protótipo do transportador considerando as necessidades do processo. Basicamente composto por uma esteira angular de correntes com transmissão através de engrenagens a um moto redutor, tendo a função de apoiar e transportar os botijões do estoque empilhados no chão até o interior da carreta, ou da carreta até o chão.

Para tanto foram analisadas a ergonomia do equipamento, angulação da esteira até a carreta, quais os tipos de correntes e eixos seriam utilizados, sistema de transmissão, a análise estrutural e materiais a serem utilizados. Segundo informações passadas pela coordenação de manutenção, para o desenvolvimento do projeto eles se basearam na metodologia apresentada no fluxograma na Figura 15.

Figura 15. Metodologia e critérios de desenvolvimento.

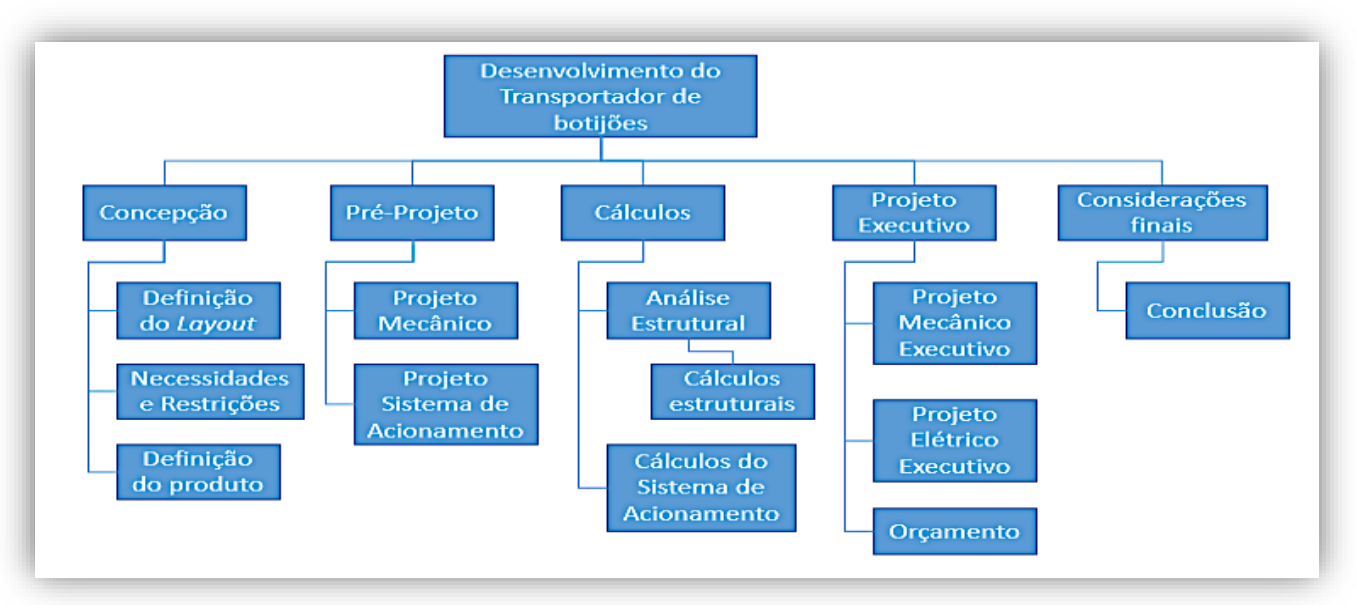

Fonte: Autores baseado em Ultragaz - unidade São José dos Campos (2017)

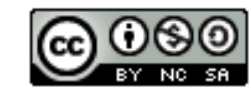


Também foi essencial a padronização das dimensões, no caso do produto e das carretas utilizadas, conforme Figura 16 e Figura 17.

Figura 16. Dimensionamento do produto

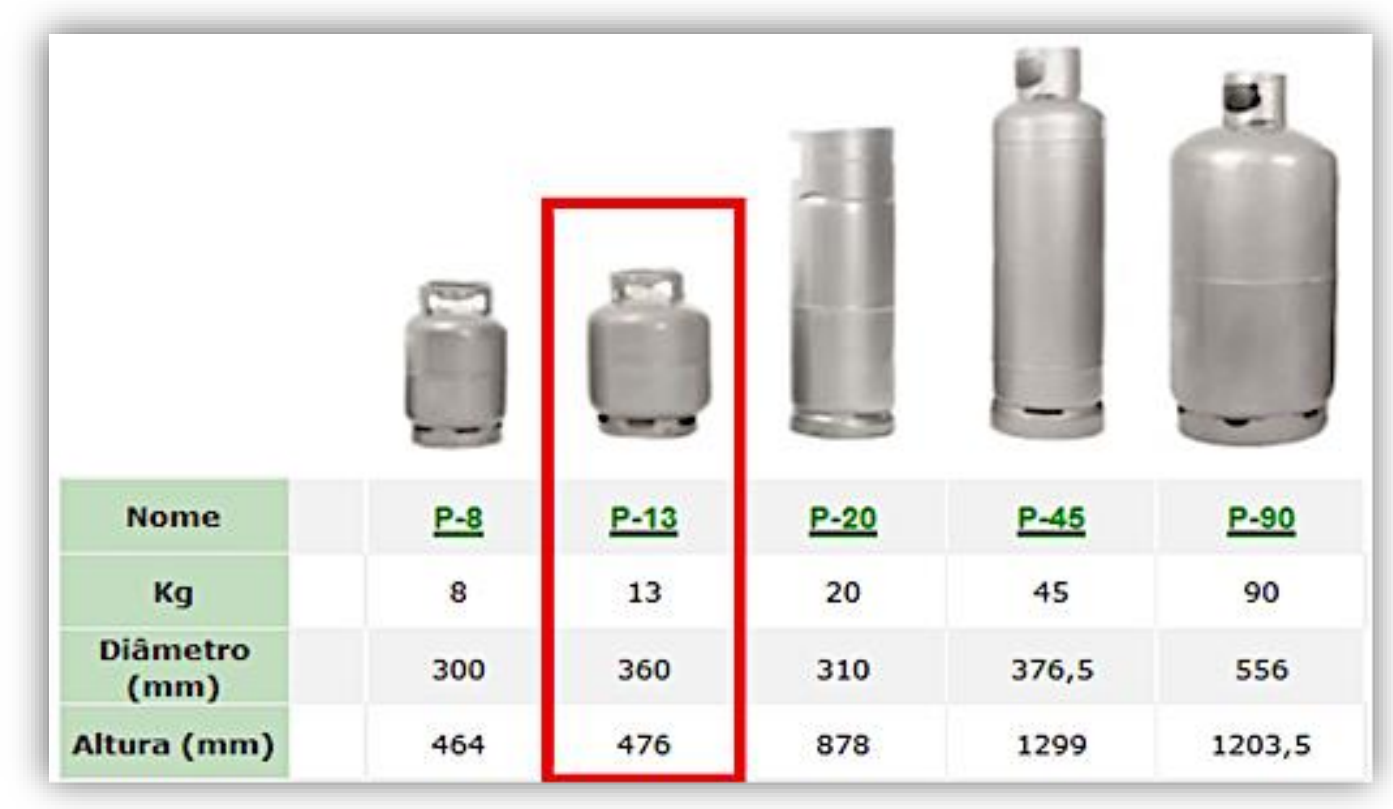

Fonte: Autores adaptado de Ultragaz - unidade São José dos Campos (2017)

Figura 17. Dimensionamento das Carretas/ Gaiolas.

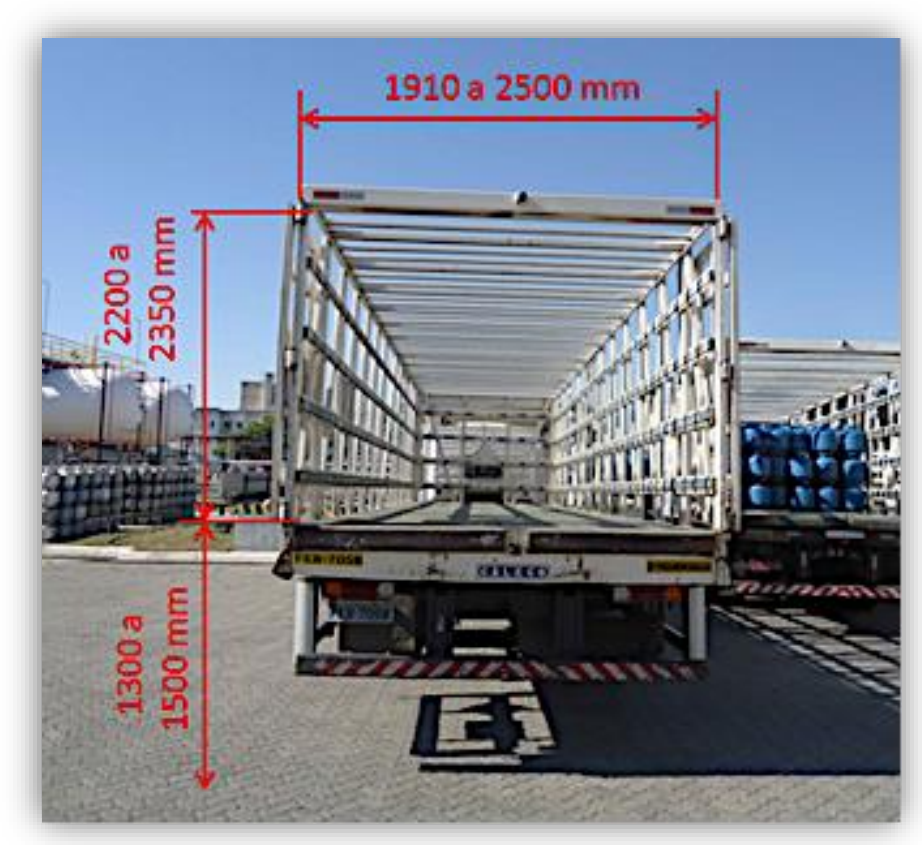

Fonte: Autores (Ultragaz- unidade São José dos Campos)

A proposta para o transportador, fabricado em aço de alta resistência, terá sua estrutura soldada para suportar as cargas de trabalho existentes durante a operação. Para garantir a locomoção do transportador entre os lotes de botijões serão utilizadas rodas com pneus, sendo duas rodas rotativas com freio de pedal na extremidade traseira e duas rodas fixas na extremidade dianteira.

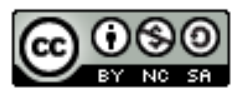


Estas rodas serão utilizadas apenas para a locomoção do transportador, pois quando o mesmo estiver em operação serão utilizados sistemas de elevação com sapatas amortecedoras, este sistema tem como objetivo nivelar a estrutura em superfícies irregulares, ajustar a altura de trabalho e absorver todo o peso da estrutura e dos botijões que estariam sendo transferidos para as rodas.

Neles serão acoplados os sistemas de transmissão que contará com um sistema esticador de correntes, este sistema é composto por um motoredutor responsável pela redução da rotação do motor. A Figura 18 descreve os detalhes da estrutura finalizada.

Junto a estrutura montada, serão acoplados um painel para coordenar as funções do transportador, que estará ligada a sensores que regularam possíveis desvios, que são acionados quando ocorre uma possível fila dos botijões entrando em contato sobre o rolete. A Figura 19 demonstra a interface do trabalho do transportador em simulação.

Figura 18. Interface da estrutura montada com os sensores.

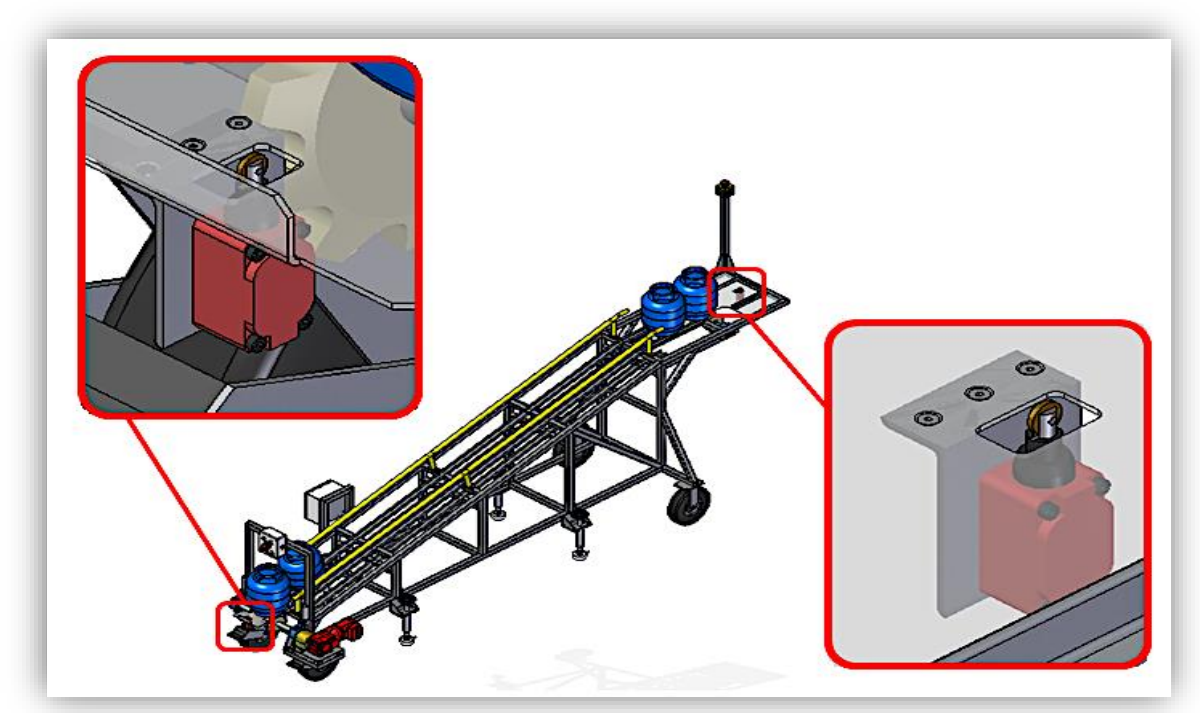

Fonte: Autores adaptado de Ultragaz - unidade São José dos Campos (2017)

Figura 19. Interface do Trabalho Geral.

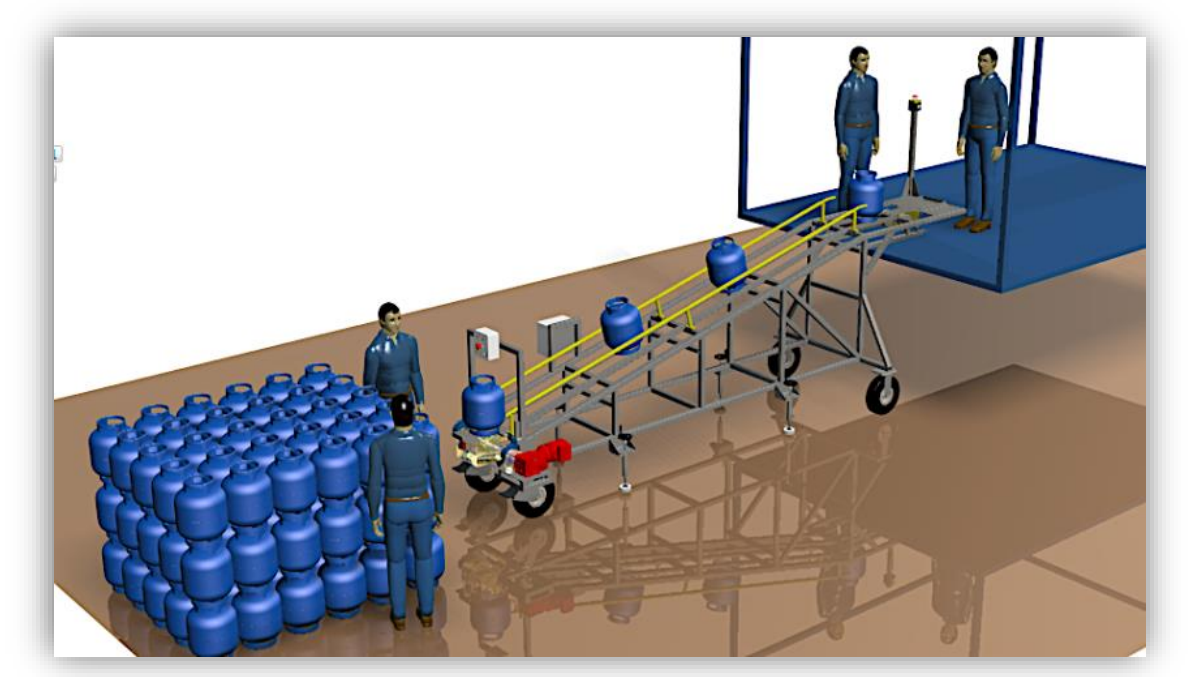

Fonte: Autores adaptado de Ultragaz - unidade São José dos Campos (2017)

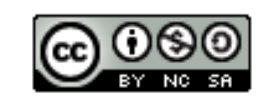




\section{Resultados Esperados}

Conforme simulações realizadas, a previsão é que com a implantação deste sistema este processo fique $30 \%$ mais ágil; espera-se também uma redução de $30 \%$ dos funcionários envolvidos, além de um grande ganho na qualidade da prestação de serviços reduzindo muito o risco de passíveis trabalhistas.

\section{CONSIDERAÇÕES FINAIS}

Portanto, conforme proposto, as operações da Base de Envasamento da Ultragaz na cidade de São José dos Campos foram analisadas e mapeadas com o objetivo de identificar nesses processos ineficiências passíveis de melhorias. Foram identificadas duas ineficiências na cadeia produtiva: o tratamento de efluentes e a logística de vasilhames de outras marcas.

Com a necessidade levantada, foi instalado na planta uma Estação de Tratamento de Efluentes, que proporcionou melhor eficiência e agilidade do processo, além de redução de custos operacionais por meio da redução da equipe de funcionários envolvidos no processo, eliminação do custo de transporte e armazenamento de tanques, redução do consumo de água e redução de custos pagos antes a empresas terceiras.

Outro processo mapeado foi a movimentação logísticas de vasilhames de outras marcas, o qual foi proposto um projeto que deverá ter seu piloto implantado na Base da Ultragaz na cidade de São José dos Campos. Nele conforme simulações, o processo será otimizado por meio da redução de $30 \%$ dos funcionários envolvidos, redução dos custos logísticos com a eliminação de uma carreta do processo, além da maior eficiência e agilidade do processo em $40 \%$, aliado a estas vantagens a melhor qualidade de trabalho aos funcionários, com melhor ergonomia e segurança, que tem como consequência a redução de passíveis trabalhistas.

\section{REFERÊNCIAS}

Agência Nacional do Petróleo, Gás Natural e Biocombustíveis, 2015 - ANP. Recuperado de www.anp.gov.br

Agência Nacional do Petróleo, Gás Natural e Biocombustíveis, 2020 - ANP. Recuperado de www.anp.gov.br

Andrade, G. E. V. (2012). Análise da Aplicação Conjunta das Técnicas SIPOC, Fluxograma e FTA em uma empresa de médio porte. ENEGEP.

Araújo, J. T. (2018). A competição no setor de GLP: o papel da marca e da logística de distribuição.

Ministério de Minas e Energia - MME/Empresa de Pesquisa Energética - EPE. (2020). Balanço Energético Nacional (BEN).

Corrêa, H. L. \& Gianesi, I. G. N. (1993). Just-in-Time, MRP II e OPT: Um enfoque estratégico. São Paulo: Atlas.

Diniz, A. C. (2005). Manual de Auditoria Integrado de Saúde, Segurança e Meio Ambiente (SSMA). 1. ed. São Paulo: Votorantim Metais.

Fernandes, R. A. S., et al., (2020). Evidências de prática de conduta anticompetitiva no mercado de gás liquefeito de petróleo (GLP) em Outro Preto-MG. Ciência Dinâmica, 17(1), 27-51.

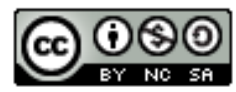


Filgueiras, E., et al. (2015). Gargalos na Infraestrutura da Cadeia De GLP para um Cenário de 10 Anos. Prêmio GLP de Inovação e Tecnologia. Edição.

Gonçalves, J. E. L. (2000). As empresas são grandes coleções de processos. Revista de Administração de Empresas (RAE), 40(1), 6-19.

Histórico. Sindigás. Recuperado de https://www.sindigas.org.br/novosite/?page_id=2968

Hunt, V. D. (1996). Process mapping: how to reengeneer your business processes. New York: John Wiley \& Sons, Inc.

International Labour Organization. (2003). Safety in numbers: pointers for the global safety at work. Geneva.

Mello, C. H. P. \& Salgado, E. G. (2005). Mapeamento dos processos em serviços: estudo de caso em duas pequenas empresas da área de saúde. In: ENEGEP, 25, Porto Alegre. Anais.

MME - Ministério de Minas e Energia. Recuperado de www.mme.gov.br

Oliveira, D. P. R. (2006). Sistemas, Organização e Métodos: uma abordagem gerencial. 18. ed. São Paulo: Atlas.

Plano Decenal de Expansão de Energia 2022. Recuperado de https://www.epe.gov.br/pt/publicacoes-dados-abertos/publicacoes/Plano-Decenal-deExpansao-de-Energia-2022

Pyzdek, T. \& Keller, P. (2011). Seis sigma: guia do Profissional, um guia completo para Green Belts, Black Belts e gerentes de todos os níveis. 3. ed. Rio de Janeiro: Alta Books.

Rasis, D., Gitlow, H. S., \& Poovich, E. (2002-03). Paper organizars international: a fictitious Six Sigma Gre'en Belt case study. I. Quality Engineering, 15(1), 127-145.

Simon, K. (2018). SIPOC Diagram. Journal Six Sigma.

Villela, C. da S. S., et al., (2000). Mapeamento de processos como ferramenta de reestruturação e aprendizado organizacional. 